\title{
Fertilizantes de leguminosas como fontes alternativas de nitrogênio para produção orgânica de alface
}

\author{
Maxwell Merçon Tezolin Barros Almeida ${ }^{(1)}$, Alice Teodorio Lixa ${ }^{(1)}$, Edmilson Evangelista da Silva ${ }^{(1)}$, \\ Pedro Henrique Sabadin de Azevedo ${ }^{(1)}$, Helvécio De-Polli(2) e Raul de Lucena Duarte Ribeiro(1)
}

\begin{abstract}
(1)Universidade Federal Rural do Rio de Janeiro, BR 465, Km 7, CEP 23890-000 Seropédica, RJ. E-mail: maxwellmercon@yahoo.com.br, alicelixa@yahoo.com.br, evangerural@yahoo.com.br, pedrosabadin@hotmail.com, lucena@ufrrj.br (2)Embrapa Agrobiologia, BR 465, Km 7, CEP 23890-000 Seropédica, RJ. E-mail: depolli@cnpab.embrapa.br
\end{abstract}

Resumo - O objetivo deste trabalho foi avaliar o potencial de dois fertilizantes de leguminosas - produtos derivados do corte, desidratação e moagem da biomassa aérea das leguminosas mucuna-cinza (Mucuna pruriens) e gliricídia (Gliricidia sepium) - como fontes alternativas de nitrogênio (N) para a produção orgânica de alface (Lactuca sativa cv. Vera), e a influência dessas adubações sobre a vida útil pós-colheita da hortaliça, em condições de laboratório. Esses fertilizantes foram empregados em cobertura e comparados com cama-de-aviário industrial, assegurando-se doses equivalentes de $\mathrm{N}$ total. $\mathrm{O}$ delineamento experimental foi o de blocos ao acaso, com cinco tratamentos e quatro repetições: T1: adubação pré-plantio, com termofosfato sílico-magnesiano + sulfato de potássio; T2: T1 + esterco bovino, em pré-plantio; T3: T2 + fertilizante de mucuna-cinza, em cobertura; T4: T2 + fertilizante de gliricídia, em cobertura; T5: T2 + cama-de-aviário em cobertura. Não houve diferença entre os fertilizantes de ambas as espécies de leguminosas e a cama-de-aviário, quanto à produtividade, teor de $\mathrm{N}$, padrão comercial e período de vida útil pós-colheita das alfaces, o que indica potencial de uso desses fertilizantes como fontes de $\mathrm{N}$ para sistemas orgânicos de produção de hortaliças.

Termos para indexação: Gliricidia sepium, Lactuca sativa, Mucuna pruriens, adubação verde, cama-de-aviário, pós-colheita.

\section{Legume fertilizers as alternative sources of nitrogen for organic lettuce production}

\begin{abstract}
The objective of this work was to evaluate the potential use of two legume fertilizers - products derived from cutting, dehydration and milling of the aerial biomass of legume plants, velvet bean (Mисипa pruriens) and gliricidia (Gliricidia sepium) - as alternative sources of $\mathrm{N}$ for organic production of lettuce (Lactuca sativa cv. Vera); and to evaluate the influence of soil fertilization on lettuce shelf life at laboratory bench condition. These fertilizers were applied on soil surface and compared to factory poultry-bed manure at equivalent total $\mathrm{N}$ doses. The experimental design consisted of randomized blocks with five treatments and four replications, as following: T1: pre-planting fertilization with magnesium thermophosphate + potassium sulphate; $\mathrm{T} 2$ : $\mathrm{T} 1+$ cattle manure in pre-planting; $\mathrm{T} 3: \mathrm{T} 2+$ velvet bean fertilizer in covering; $\mathrm{T} 4: \mathrm{T} 2+$ gliricidia fertilizer in covering; and T5: T2 + poultry-bed manure in covering. Fertilizers of both legume species were not statistically different of poultry-bed manure, regarding productivity, $\mathrm{N}$ content, commercial standard and shelf life of lettuce, which indicates promising potential for their use in organic horticultural production systems.
\end{abstract}

Index terms: Gliricidia sepium, Lactuca sativa, Mucuna pruriens, green manuring, poultry-bed manure, postharvest.

\section{Introdução}

A alface (Lactuca sativa L.) é uma das poucas hortaliças consumidas exclusivamente in natura, possuindo por isto, alto valor agregado quando produzida sem agrotóxicos. O cultivo orgânico dessa hortaliça, além de ecologicamente correto, gera um produto com melhores características sensoriais e de maior vida útil pós-colheita, em comparação aos sistemas convencionais (Mello et al., 2003).
Apesar de um propalado crescimento, de mais de $20 \%$ ao ano (Ormond et al., 2002), a produção orgânica de alimentos tem como um dos principais entraves, a pouca disponibilidade de fontes eficazes de $\mathrm{N}$, de baixo custo, e admitidas pelas normas técnicas vigentes (Brasil, 1999; FAO, 2007). Fertilizantes orgânicos tais como: estercos, compostos e resíduos agroindustriais têm sido amplamente empregados para provisão de $\mathrm{N}$, mas são insuficientes para suprir a agricultura orgânica mundial. Assim, a adubação verde com leguminosas assume 
relevância, em razão de levar, via fixação biológica de $\mathrm{N}_{2}(\mathrm{FBN})$, grandes quantidades desse macronutriente, minimizar a dependência de insumos externos e tornar possível a auto-suficiência em $\mathrm{N}$ na unidade de produção (Espindola et al., 2005). No entanto, as tradicionais práticas de adubação verde, em rotação ou consórcio, dificilmente prescindem de adubação com outras fontes orgânicas de $\mathrm{N}$ para que produções satisfatórias sejam alcançadas. Geralmente, menos de $30 \%$ do N contido nos resíduos de leguminosas são recuperados pelas culturas (Giller \& Cadisch, 1995; Peoples et al., 1995; Fillery, 2001; Crews \& Peoples, 2005). Além disso, em culturas com espaçamentos reduzidos, como alface, salsa e cebolinha, a adubação verde em rotação ocupa área que poderia ser ocupada por uma cultura econômica, que depois de cortada, ofereceria dificuldade para o plantio sob a palhada. Em consórcio, existe o problema de competição por água, luz e nutrientes e dificuldade de manejo. Além disto, existe a dificuldade em sincronizar-se a provisão de $\mathrm{N}$ e sua demanda pelas culturas, considerada por Campbell et al. (1995), Crews \& Peoples (2005) e Espindola et al. (2005) como o ponto chave para melhoria da eficiência da adubação verde.

Acredita-se que a transformação da biomassa aérea de determinadas espécies de leguminosas/fabáceas, com elevado potencial de fixação biológica de $\mathrm{N}_{2}$, acúmulo de $\mathrm{N}$ e facilidade de manejo, em fertilizantes de leguminosas - produtos derivados do corte, desidratação e moagem da biomassa aérea dessas plantas - possa tornar mais prática e eficiente a adubação verde (Almeida, 2007). Essa tecnologia, além de melhorar as características químicas (menor teor de água) e físicas (maior densidade e homogeneidade) da matéria-prima, por facilitar seu transporte, armazenamento e aplicação, possibilita seu uso em quantidades e épocas adequadas, o que favorece a sincronia da provisão de $\mathrm{N}$.

O objetivo deste trabalho foi avaliar o potencial de dois fertilizantes de leguminosas mucuna-cinza (Mисиna pruriens) e gliricídia (Gliricidia sepium), como fontes alternativas de $\mathrm{N}$, para a produção orgânica de alface (Lactuca sativa, cultivar Vera), e a influência dessas adubações sobre a vida útil pós-colheita da hortaliça, em condições de laboratório.

\section{Material e Métodos}

As leguminosas, mucuna-cinza e gliricídia, foram cultivadas no Sistema Integrado de Produção Agroecológica (SIPA), localizado no Município de
Seropédica, RJ, a $22^{\circ} 45^{\prime} \mathrm{S}, 43^{\circ} 40^{\prime} \mathrm{W}$, e altitude de $33 \mathrm{~m}$. A seleção das espécies levou em consideração a elevada adaptação local, rusticidade, produção de biomassa e o acúmulo de $\mathrm{N}$ na parte aérea das plantas.

A mucuna-cinza foi semeada em dezembro de 2004, e cortada após 135 dias. A biomassa foi imediatamente transportada para casa de vegetação pavimentada, para secagem. A biomassa fresca foi espalhada sobre o pavimento em camada de aproximadamente $15 \mathrm{~cm}$ de espessura, sem revolvimento, por uma semana, até atingir cerca de $6 \%$ de umidade. A temperatura do ar variou entre $20 \mathrm{e} 45^{\circ} \mathrm{C}$. Em seguida, foi levada para um galpão, onde permaneceu até o momento da moagem. Foi triturada em moinho de martelos, equipado com peneira de $3 \times 13 \mathrm{~mm}$ e ciclone. Foram produzidos cerca de $80 \mathrm{~kg}$ desse fertilizante.

O fertilizante de gliricídia foi processado a partir da recepagem de árvores com cerca de dois anos de idade. Os troncos foram cortados a $0,5 \mathrm{~m}$ de altura, com auxílio de moto-serra, e a desidratação ocorreu em campo, sobre lona de polietileno preto. Após a secagem, os galhos foram removidos, e o material remanescente (folíolos e pecíolos) triturado em moinho de facas com abertura de malha de $2 \mathrm{~mm}$ de diâmetro. Foram produzidos cerca de $40 \mathrm{~kg}$ desse fertilizante. Em razão da ocorrência de chuvas, a desidratação desse material durou 15 dias, e foi retirado do campo com cerca de $6 \%$ de umidade. Terminada as operações de moagem, os fertilizantes de leguminosas foram armazenados em sacolas de polietileno.

A cama-de-aviário, constituída de maravalha, foi adquirida de estabelecimento industrial, tendo sido oriunda de galpão de frangos para abate. O esterco bovino, utilizado em pré-plantio, foi procedente de rebanho do SIPA, manejado a pasto, sem agrotóxicos ou ração balanceada. Para fins de homogeneização e redução do erro experimental, a cama-de-aviário e o esterco bovino, ambos curtidos, foram peneirados em malha de $6,5 \mathrm{~mm}$ e estocados em um galpão coberto.

Os insumos foram caracterizados a partir de quatro amostras compostas de cada fertilizante orgânico. Essas amostras foram secadas em estufa com ventilação forçada, a $65^{\circ} \mathrm{C}$ por 96 horas, processadas em moinho Wiley, transferidas para moinho de bola, onde permaneceram por 48 horas. Em seguida, as amostras foram acondicionadas em frascos de acrílico que, antes de serem tampados, permaneceram em estufa a $65^{\circ} \mathrm{C}$ por 20 horas. Os teores de $\mathrm{P}, \mathrm{K}, \mathrm{Ca}$ e $\mathrm{Mg}$ foram determinados após digestão nítrico-perclórica: $\mathrm{P}$, por 
espectrometria de absorção óptica, após formação do complexo fosfato-molibdato na presença de ácido ascórbico; $\mathrm{Ca}$ e $\mathrm{Mg}$, por espectrometria de plasma; e $\mathrm{K}$, por espectrometria de chama. O teor de $\mathrm{N}$ foi determinado, após digestão sulfúrica, pelo método Kjeldahl, e o teor de C, por gravimetria, após secagem em estufa a $105^{\circ} \mathrm{C}$, por 4 horas, e queima em mufla a $550^{\circ} \mathrm{C}$, por 2 horas.

$\mathrm{O}$ experimento foi conduzido em área do SIPA, em canteiros de 6,5 m de comprimento por 1,0 $\mathrm{m}$ de largura, levantados com auxílio de roto-encanteiradora tratorizada. O solo foi classificado como Argissolo Vermelho-Amarelo, e a área encontrava-se em pousio por mais de dois anos. Antes do encanteiramento, a vegetação espontânea, com alta predominância de gramíneas e ciperáceas foi roçada e removida. A análise do solo $(0,0-0,2 \mathrm{~m})$ apresentou os seguintes resultados: pH em água, 6,1; $\mathrm{Al}, 0,0 \mathrm{cmol}_{\mathrm{c}} \mathrm{dm}^{-3} ; \mathrm{Ca}, 1,5 \mathrm{cmol}_{\mathrm{c}} \mathrm{dm}^{-3}$; $\mathrm{Mg}, 0,9 \mathrm{cmol}_{\mathrm{c}} \mathrm{dm}^{-3}$; P (Mehlich-1), 123,0 mg dm${ }^{-3} ; \mathrm{K}$, 69,0 mg dm${ }^{-3}$; C, 6,0 $\mathrm{g} \mathrm{kg}^{-1}$; N, 0,68 $\mathrm{g} \mathrm{kg}^{-1}$; argila, $83 \mathrm{~g} \mathrm{~kg}^{-1}$; areia, $876 \mathrm{~g} \mathrm{~kg}^{-1}$; e silte, $41 \mathrm{~g} \mathrm{~kg}^{-1}$, determinados segundo Embrapa (1997).

O delineamento experimental consistiu de blocos casualizados, com cinco tratamentos e quatro repetições. Com o intuito de se elevar os teores de macro e micronutrientes ( $\mathrm{P}, \mathrm{K}, \mathrm{Ca}, \mathrm{Mg}, \mathrm{S}, \mathrm{B}, \mathrm{Zn}, \mathrm{Mn}, \mathrm{Cu}$ e Mo) no solo, deixando-se $\mathrm{N}$ como o principal nutriente limitante, foi realizada adubação pré-plantio com termofosfato sílico-magnesiano e sulfato de potássio (Tabela 1) - fertilizantes admitidos pelas normas técnicas de agricultura orgânica (Brasil, 1999; FAO, 2007). Os tratamentos foram aplicados em parcelas de $1 \mathrm{~m}^{2}$, distantes entre si e das extremidades, por $0,25 \mathrm{~m}$; em que: T1: adubação pré-plantio com termofosfato sílicomagnesiano + sulfato de potássio; $\mathrm{T} 2: \mathrm{T} 1$ + esterco bovino em pré-plantio; T3: T2 + fertilizante de mucunacinza em cobertura; $\mathrm{T} 4: \mathrm{T} 2$ + fertilizante de gliricídia em cobertura; T5: T2 + cama-de-aviário em cobertura (Tabela 1). As adubações pré-plantio foram realizadas três dias antes do transplantio das mudas de alface, pela incorporação dos adubos $(0,00-0,07 \mathrm{~m})$ com auxílio de um rastelo, e as de cobertura, no 70 e $22^{\circ}$ dia após o transplantio (DAT), pela distribuição uniforme dos fertilizantes na superfície da parcela. Os fertilizantes utilizados foram, previamente, pesados em balança digital de precisão, e acondicionados em sacolas de polietileno, conforme o tratamento. As dosagens dos fertilizantes orgânicos foram estipuladas com base na equivalência de $\mathrm{N}$ total fornecido à cultura (Tabela 1 ). Duas capinas manuais foram necessárias, com remoção das plantas infestantes do canteiro. A irrigação foi realizada por intermédio de microaspersores instalados nos espaços entre as parcelas e nas extremidades dos blocos.

O transplantio das mudas de alface, cultivar Vera (grupo crespa), foi realizado no espaçamento de $0,25 \times 0,25 \mathrm{~m}$, em 22 de agosto de 2005. Essas mudas foram produzidas em bandejas de poliestireno expandido de 200 células, em casa de vegetação, com substrato formulado no próprio SIPA, constituído de subsolo argiloso, esterco bovino curtido e vermicomposto, nas proporções respectivas de 2:1:1 (base volumétrica).

As colheitas ocorreram em duas épocas, aos $37 \mathrm{e}$ aos 44 dias após o transplantio. As alfaces foram cortadas rente ao solo, submetidas a uma pré-limpeza,

Tabela 1. Composição química dos fertilizantes, dosagens e nutrientes fornecidos.

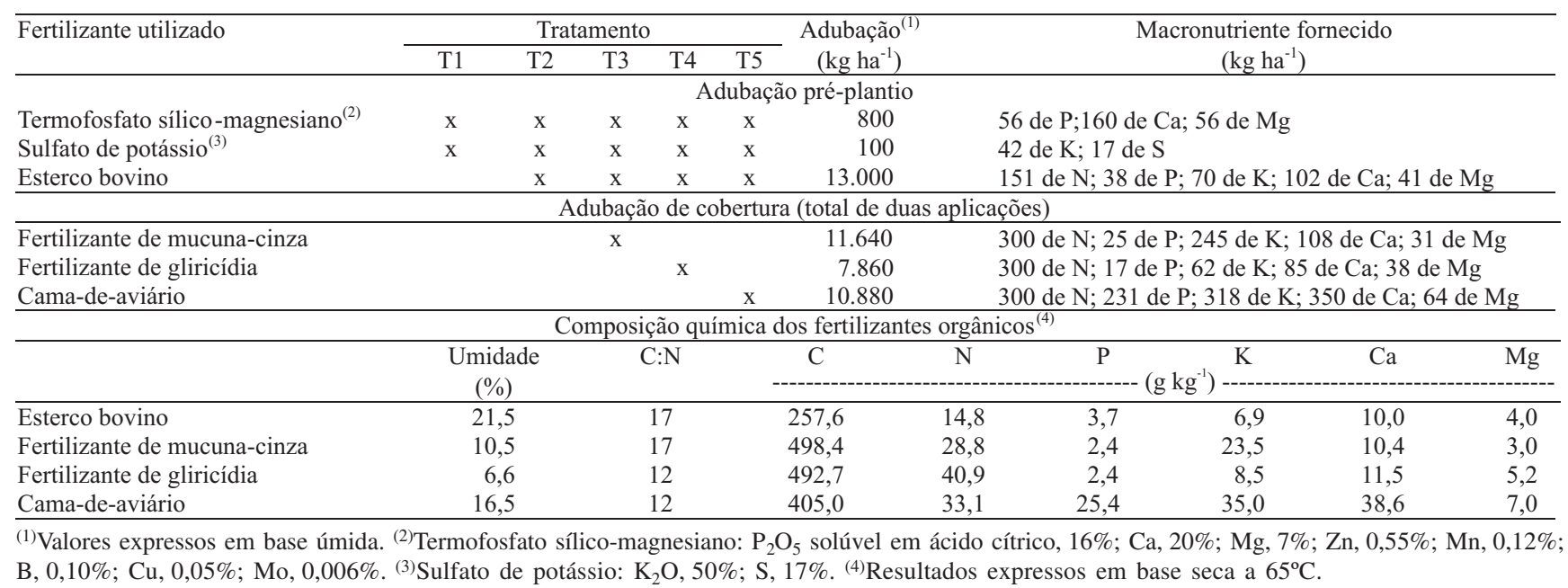


em que as folhas baixeiras, senescentes ou lesionadas, foram descartadas, e a cabeça remanescente lavada em água corrente.

Na primeira colheita (37 DAT), a área útil foi representada pelas quatro plantas centrais de cada parcela, das quais foram avaliadas variáveis referentes à parte aérea: massa de matéria fresca (determinada em balança digital de precisão, após eliminação do excesso de água sobre as folhagens); massa de matéria seca (determinada em balança digital de precisão, após pré-secagem em casa de vegetação por 24 horas, seguida de secagem em estufa com ventilação forçada a $65^{\circ} \mathrm{C}$, por cinco dias); diâmetro médio (média de dois diâmetros medidos em cruz, iniciando-se pelo maior diâmetro); número de folhas (folhas com mais de $5 \mathrm{~cm}$ de comprimento); teor de $\mathrm{N}$ na matéria seca, pelos procedimentos descritos para análise dos fertilizantes orgânicos, e acúmulo de $\mathrm{N}$ na parte aérea.

Na segunda colheita (44 DAT), apenas os tratamentos cujas alfaces atingiram padrão comercial (T3, T4 e T5) foram considerados, tendo sido coletadas três plantas por parcela, que, além da pré-limpeza, receberam ensacamento individualizado, para conferir maior proteção contra danos mecânicos, que poderiam reduzir o tempo de vida útil pós-colheita das alfaces (Chitarra \& Chitarra, 2005). Foram colhidas 36 alfaces, todas sem defeitos como perfurações, manchas ou sintomas de doença, que permaneceram em local sombreado até que fossem transportadas para um dos laboratórios da Embrapa Agrobiologia, situado a poucos minutos do SIPA. Neste local, as embalagens foram abertas, iniciando-se as avaliações de massa de matéria fresca, diâmetro médio, número de folhas por planta e teor de sólidos solúveis (TSS).

Uma planta de cada parcela foi destinada para avaliação inicial do teor de sólidos solúveis e as outras duas destinadas às avaliações relativas à conservação pós-colheita. Essas alfaces foram colocadas sobre folhas de papel A4, em bancada azulejada, em delineamento de blocos casualizados, com três tratamentos e quatro repetições. Considerou-se como nula a perda de massa de matéria fresca do corte até a primeira pesagem no laboratório. A segunda pesagem ocorreu 24 horas após a colheita, as 11 seguintes, a intervalos de $12 \mathrm{em} 12$ horas, e a pesagem final, 18 horas após a penúltima. Depois de cada pesagem, foi realizado um giro de $180^{\circ}$, antes de retornar a alface para folha de papel. O estudo totalizou 174 horas, e os dados foram expressados na forma de perda acumulada de massa de matéria fresca durante esse período. Por ocasião das pesagens, a aparência das alfaces foi classificada, por três pessoas, considerando-se a seguinte escala de padrão comercial: excelente, muito bom, bom, regular, ruim e péssimo.

No final do experimento, foi realizada nova mensuração do TSS, que foi determinado com auxílio de um refratômetro de campo do sumo da nona folha, com mais de $5 \mathrm{~cm}$, contada de dentro para fora. A folha foi retirada, secada em papel toalha, macerada em gral de porcelana, até tomar consistência de pasta, em seguida, foi comprimida manualmente deixando-se cair duas gotas do sumo sobre a lente do refratômetro, procedendo-se à leitura em ${ }^{\circ}$ Brix. Durante o período das avaliações pós-colheita, a temperatura ambiente e a umidade relativa do ar, registradas por um termoigrógrafo instalado sobre a bancada, variaram entre 24 e $25^{\circ} \mathrm{C}$ e entre 76 e $80 \%$, respectivamente.

Depois de verificado o atendimento às pressuposições de normalidade e homogeneidade da variância dos erros, as médias das variáveis foram submetidas à análise de variância $(p<0,05)$, seguida de análise de regressão, com respeito à perda acumulada de massa de matéria fresca em pós-colheita, recorrendo-se ao teste de Tukey, a 5\% de probabilidade para comparação entre as médias das demais variáveis. As análises foram realizadas nos softwares Microsoft Excel, SAEG, da Universidade Federal de Viçosa, e SISVAR, da Universidade Federal de Lavras, sendo adotado o modelo de parcelas subdivididas no tempo, quando as avaliações incidiam sobre a mesma parcela, em épocas diferentes.

\section{Resultados e Discussão}

Verificou-se que as adubações de cobertura (T3, T4 e T5) contribuíram para o aumento da produtividade da alface, tendo proporcionado ganhos em matéria fresca, matéria seca, diâmetro médio da parte aérea e de número de folhas por planta (Figura 1). Essas adubações colaboraram efetivamente para disponibilização de formas absorvíveis de $\mathrm{N}$ no solo, o que foi evidenciado pela maior concentração e pelo acúmulo de $\mathrm{N}$ na parte aérea da alface dos tratamentos T3, T4 e T5 (Figura 1). Diferenças significativas não foram detectadas entre esses tratamentos, com referência ao teor de $\mathrm{N}$ no tecido da alface. Entretanto, o fertilizante de gliricídia (T4) proporcionou maior acúmulo de $\mathrm{N}$ do que a cama-deaviário (T5), não diferindo estatisticamente do tratamento com fertilizante de mucuna-cinza (T3). Em experimento com rúcula (Eruca sativa L.), ao 
comparar eficiência dos fertilizantes de mucuna-cinza, gliricídia e da cama-de-aviário em doses equivalentes de $\mathrm{N}$ total, o fertilizante de gliricídia foi o que proporcionou a maior recuperação relativa de $\mathrm{N}$ (Almeida, 2007). A granulometria mais fina do

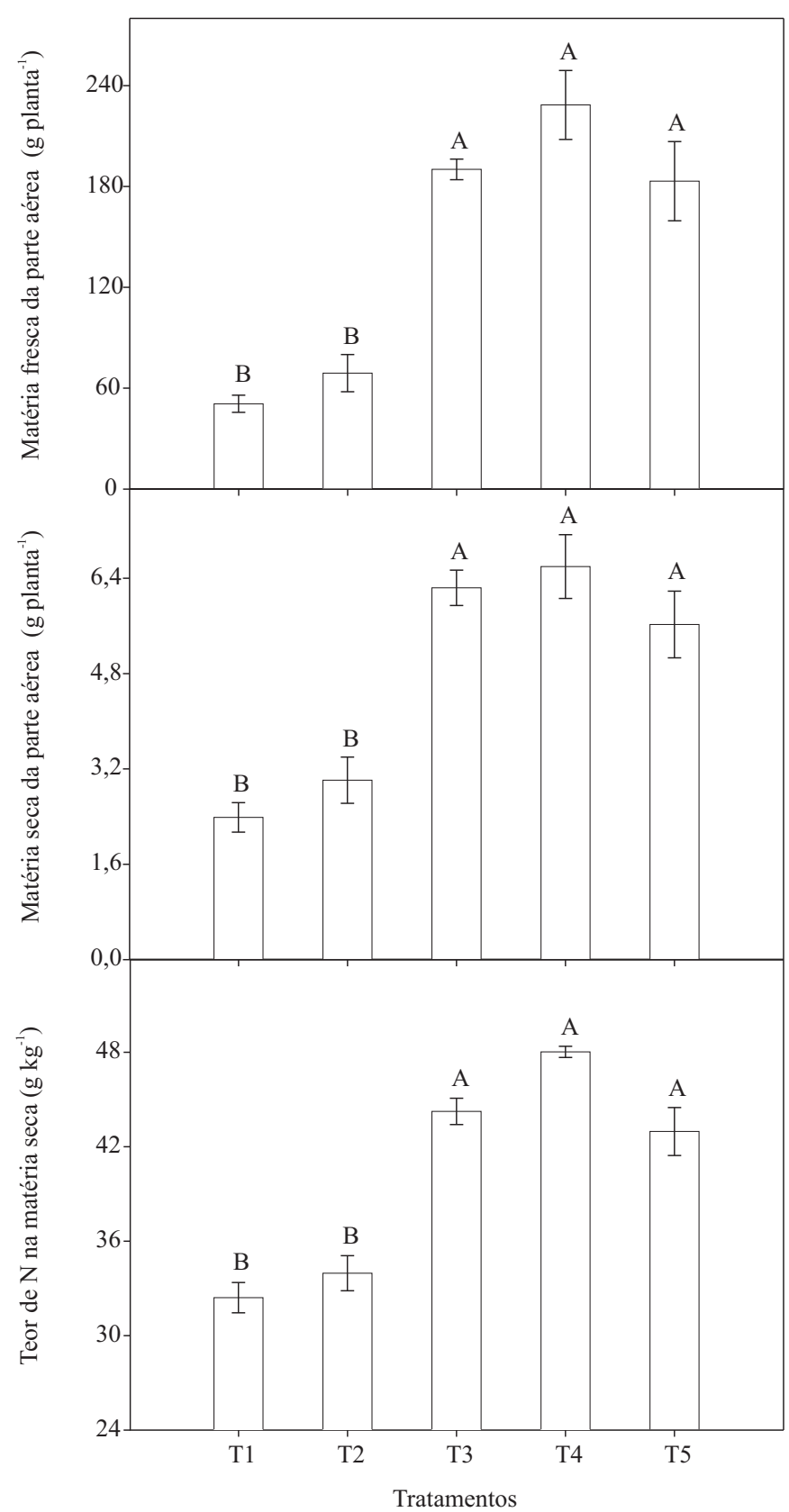

fertilizante de gliricídia, que permite maior interface de contato fertilizante-solo, aliada à elevada qualidade química desse insumo, ao alto teor de $\mathrm{N}$ (Tabela 1) e aos baixos teores de lignina, polifenóis e de substâncias que dificultam a mineralização protéica (Handayanto et al., 1997),

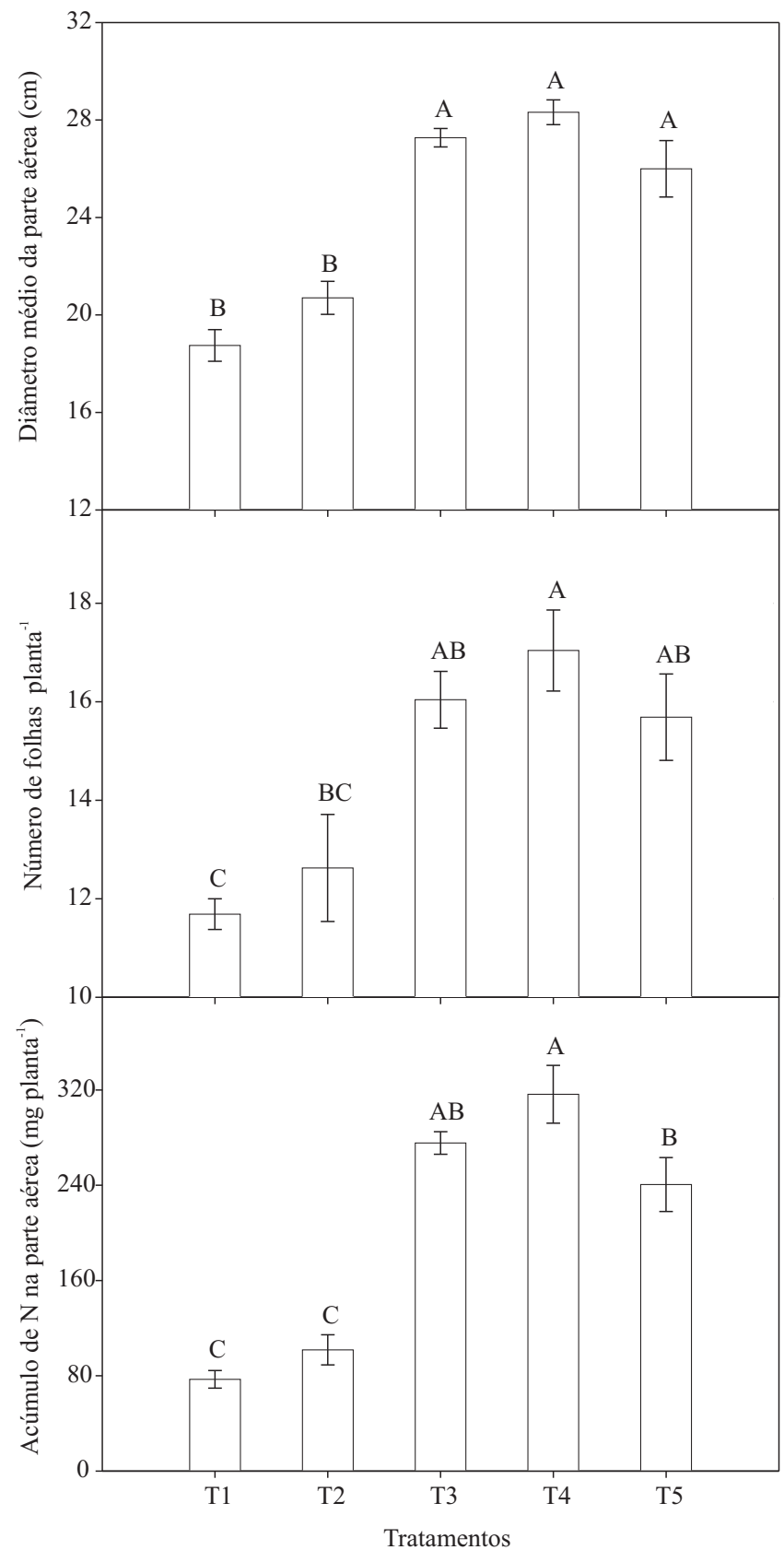

Figura 1. Valores médios de massa de matéria fresca, diâmetro médio, massa de matéria seca, número de folhas, teor de $\mathrm{N}$ na matéria seca e acúmulo de $\mathrm{N}$ na parte aérea de alface (cultivar Vera), conduzida sob manejo orgânico e colhida aos 37 dias após o transplantio, em função de diferentes fórmulas de adubação utilizadas. Barras sobre as colunas representam o erro-padrão da média. Letras sobre as barras comparam os tratamentos pelo teste de Tukey, a 5\% de probabilidade. T1: adubação pré-plantio com termofosfato sílico-magnesiano + sulfato de potássio; T2: T1 + esterco bovino em pré-plantio; T3: T2 + fertilizante de mucuna-cinza em cobertura; T4: T2 + fertilizante de gliricídia em cobertura; T5: T2 + cama-de-aviário em cobertura. 
justificam o alto potencial de biodisponibilização de $\mathrm{N}$ desse fertilizante.

Os teores médios de $\mathrm{N}$ nas alfaces tratadas com os fertilizantes de gliricídia $\left(48,0 \mathrm{~g} \mathrm{~kg}^{-1}\right)$ e mucuna-cinza (43,0 $\left.\mathrm{g} \mathrm{kg}^{-1}\right)$ foram estatisticamente semelhantes aos das tratadas com cama-de-aviário $\left(44,2 \mathrm{~g} \mathrm{~kg}^{-1}\right)$ (Figura 1) e próximos aos encontrados por Turazi et al. (2006), $44,1 \mathrm{~g} \mathrm{~kg}^{-1}$, e Oliveira et al. (2006), 43,0 $\mathrm{g} \mathrm{kg}^{-1}$, que também trabalharam com cultivares do grupo crespa, porém adubadas com quantidades muito superiores de cama-de-aviário, 22 e $28 \mathrm{Mg} \mathrm{ha}^{-1}$, respectivamente. Esses resultados confirmam o potencial dos fertilizantes de leguminosas como fontes alternativas de $\mathrm{N}$ para produção orgânica de hortaliças, e assumem relevância, tendo em vista que a cama-de-aviário industrial, uma das fontes orgânicas de $\mathrm{N}$ mais utilizadas e eficazes, têm seu emprego restringido em agricultura orgânica (Brasil, 1999; FAO, 2007).

A adubação orgânica exclusiva com esterco bovino (T2) não contribuiu de forma efetiva para o aumento de produtividade da alface, pois não foi possível observar ganho significativo, em relação ao controle (T1), para nenhuma das variáveis fitotécnicas avaliadas (Figura 1). A baixa eficiência da adubação com esterco bovino, também foi observada por Turazi et al. (2006).

Na segunda colheita (44 DAT), as plantas do T3, T4 e T5 exibiam padrão de comercialização com coloração esverdeada, turgidez, vivacidade e massa de matéria fresca variando entre 198 e $322 \mathrm{~g}$. Em contrapartida, as alfaces dos outros dois tratamentos apresentavam-se amareladas e pequenas e não foram, por isso, incluídas nas avaliações. Assim como na primeira colheita, as alfaces do T3, T4 e T5 não apresentaram diferenças significativas com referência à matéria fresca ( $\mathrm{p}=0,2329)$, diâmetro médio $(\mathrm{p}=0,0698)$ e número de folhas por planta $(p=0,7823)$. No entanto, foi constatado que aos 37 DAT as plantas ainda não haviam adquirido seu máximo desenvolvimento (Figura 2). A produtividade média passou de aproximadamente $32 \mathrm{Mg} \mathrm{ha}^{-1}$ (aos 37 DAT) para $40 \mathrm{Mg} \mathrm{ha}^{-1}$ (aos 44 DAT), o que significa aumento da ordem de $24 \%$.

A colheita da alface deve ser realizada logo que ela atinja o máximo desenvolvimento, porém com folhas ainda tenra, com bom sabor e sem nenhum sinal de pendoamento (Filgueira, 2003). A idade da planta é o fator que mais influi na perda de massa de matéria fresca da alface, na fase de pós-colheita, e plantas jovens são mais suscetíveis à perda de água do que plantas adultas (Poulsen et al., 1994), sendo este um dos principais fatores para o descarte do produto (Nam, 2000; Chitarra \& Chitarra, 2005). Nesse sentido, a colheita aos 44 DAT foi mais apropriada do que a realizada aos 37 DAT (Figura 2).

As curvas de perda acumulada de massa de matéria fresca das alfaces, adubadas com os fertilizantes de mucuna-cinza, gliricídia e com a cama-de-aviário não diferiram entre si (Figura 3). Conforme o esperado, as maiores taxas de perda ocorreram nas primeiras 36 horas após a colheita (Figura 2), quando o conteúdo de água é mais alto e retido com menos força. É interessante ressaltar que mesmo tendo sido empregadas fontes de $\mathrm{N}$ de diferentes composições, sujeitas a diferentes dinâmicas de mineralização e absorção de $\mathrm{N}$ pela cultura, o tempo de vida útil pós-colheita das alfaces não foi influenciado. Trabalhos realizados por Poulsen et al. (1994) e Evans (1998) comprovam que N é um dos fatores que menos influenciam a queda da qualidade da alface, ao longo do período de pós-colheita.

Santos et al. (2001), sob condições semelhantes de conservação pós-colheita (temperatura média de $23^{\circ} \mathrm{C}$ e $70 \%$ de UR), com a cultivar Babá (grupo lisa), verificaram que as menores perdas de massa de matéria

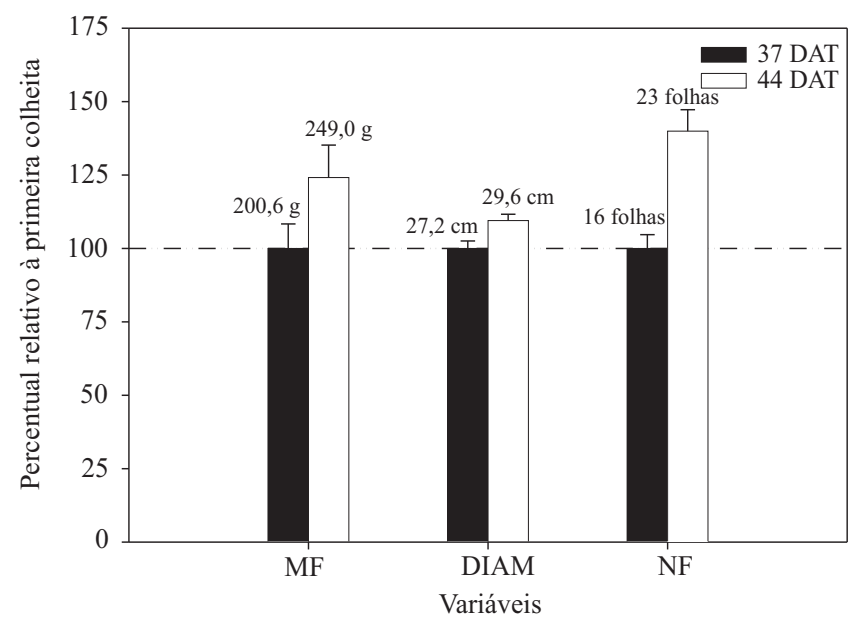

Figura 2. Percentual médio relativo de massa de matéria fresca (MF), diâmetro médio (DIAM) e número de folhas (NF) por planta na parte aérea de alface (cultivar Vera), conduzida sob manejo orgânico, e colhida aos 37 e 44 dias após o transplantio. Barras sobre as colunas representam o erro-padrão da média. Números sobre as barras representam a média entre T3, T4 e T5, com diferentes adubações de cobertura: fertilizante de mucuna-cinza, fertilizante de gliricídia e cama-de-aviário. Não foi detectada diferença estatística entre os tratamentos $(p>0,05)$. Ocorreram diferenças significativas $(p<0,05)$ entre as épocas de colheita, para todas as variáveis analisadas. 
fresca corresponderam às doses mais elevadas de composto orgânico, não havendo efeito da adubação mineral com NPK. A menor perda acumulada de massa de matéria fresca obtida por estes autores (dose de 91,2 $\mathrm{Mg} \mathrm{ha}^{-1}$ de composto, em base seca), 84 horas após a colheita, foi de $38,6 \%$. Este valor só foi alcançado neste trabalho 133 horas após a colheita, 49 horas após o tratamento que teve menor perda, conforme Santos et al. (2001). Diferenças entre cultivares, condições de cultivo e umidade relativa do ar durante a estocagem devem ter influenciado a discrepância entre os resultados.

A qualidade visual das alfaces decaiu ao longo do tempo e de forma semelhante nos três tratamentos, tendo sido classificada como excelente, entre 0-24 horas após a colheita; muito boa, de 36-48 horas; boa, de 60-72 horas; regular, de 84-108 horas, ruim, as 120 horas e péssima, de 132-174 horas. Apesar da subjetividade da classificação, pode-se afirmar que as alfaces poderiam ser facilmente comercializadas com até 48 horas após a colheita. Tendo em vista que a principal causa da perda da qualidade das alfaces foi a perda de turgescência, é bem provável que o simples uso de embalagens microperfuradas, que promovem redução da transpiração, prolongasse a vida útil póscolheita das alfaces.

O teor de sólidos solúveis (TSS) variou entre as datas de avaliação $(p=0,0009)$, mas não diferiu entre os tratamentos $(\mathrm{p}=0,1792)$. No primeiro dia, o valor médio

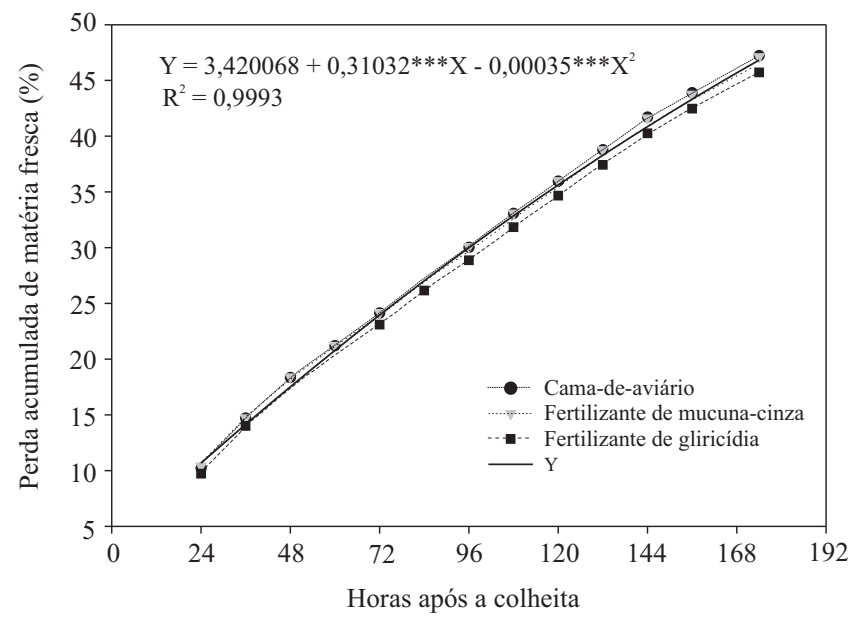

Figura 3. Perda acumulada de massa de matéria fresca, em bancada do laboratório, de alface (cultivar Vera), conduzida sob manejo orgânico e colhida aos 44 dias após o transplantio das mudas, em razão de três tipos de adubação orgânica de cobertura. ${ }^{* * *}$ Significativo a $1 \%$ de probabilidade, pelo teste $\mathrm{F}$. de TSS foi de $4,4^{\circ}$ Brix, enquanto no sétimo dia, foi de $6,4^{\circ} \mathrm{Brix}$. O valor encontrado no primeiro dia foi próximo ao de Roversi \& Masson (2004), 4, $2^{\circ}$ Brix, para alface Verônica (grupo crespa) e superior à faixa encontrada por Bezerra Neto et al. (2005), de 3,2 a 3,6 ${ }^{\circ}$ Brix, para a variedade Tainá (grupo americana). No entanto, Roversi \& Masson (2004) constataram decréscimo desse valor ao longo do tempo, em alface minimamente processada e refrigerada a $5-7^{\circ} \mathrm{C}$, em razão da respiração da hortaliça. $\mathrm{O}$ aumento do TSS, observado neste trabalho, deve estar relacionado ao decréscimo do conteúdo de água na folha analisada, que promoveu aumento do conteúdo relativo de sólidos solúveis.

Alguns autores consideram o TSS como um importante atributo para previsão do tempo de vida útil pós-colheita da alface (Varoquaux et al., 1996). De modo geral, quanto maior o TSS da alface, recém-colhida, maior o período em que sua qualidade pode ser preservada. Neste trabalho, parece que o TSS foi bom indicador para previsão do potencial de conservação das alfaces, já que apresentou correspondência com os demais atributos de pós-colheita avaliados.

\section{Conclusões}

1. Os fertilizantes de leguminosas são fontes promissoras de nitrogênio para a produção orgânica de hortaliças, capazes de substituir a adubação de cobertura com cama-de-aviário industrial, em dosagem equivalente de nitrogênio total.

2. O fertilizante de gliricídia é mais eficiente do que a cama-de-aviário na provisão de nitrogênio.

3. O tempo de vida útil pós-colheita da alface não é influenciado pelo tipo de fertilizante orgânico aplicado em cobertura.

\section{Agradecimentos}

À Coordenação de Aperfeiçoamento de Pessoal de Nível Superior e ao Conselho Nacional de Desenvolvimento Científico e Tecnológico, pelo suporte financeiro.

\section{Referências}

ALMEIDA, M.M.T.B. Fertilizantes de leguminosas: tecnologia inovadora de adubação verde para provisão de nitrogênio em sistemas orgânicos de produção. 2007. 83p. Dissertação (Mestrado) - Universidade Federal Rural do Rio de Janeiro, Seropédica. 
BEZERRA NETO, F.; BARROS JÚNIOR, A.P.; SILVA, E. de O.; SILVEIRA, L.M. da; AROUCHA, E.M.M. Qualidade da alface em sistemas consorciados com cenoura sob diferentes densidades populacionais das culturas componentes. Caatinga, v.18, p.169-175, 2005.

BRASIL. Ministério da Agricultura Pecuária e Abastecimento. Instrução Normativa no 7, de 17 de maio de 1999. Estabelece as normas de produção, tipificação, processamento, envase, distribuição, identificação e de certificação da qualidade para os produtos orgânicos de origem vegetal e animal. Diário Oficial [da] República Federativa do Brasil, Brasília, DF, 19 maio 1999, Seção 1, p.11.

CAMPBELL, C.A.; MYERS, R.J.K.; CURTIN, D. Managing nitrogen for sustainable crop production. Nutrient Cycling in Agroecosystems, v.42, p.277-296, 1995.

CHITARRA, M.I.F.; CHITARRA, A.B. Pós-colheita de frutas e hortaliças: fisiologia e manuseio. 2.ed. rev. amp. Lavras: UFLA, 2005. 785p.

CREWS, T.E.; PEOPLES, M.B. Can the synchrony of nitrogen supply and crop demand be improved in legume and fertilizer-based agroecosystems? A review. Nutrient Cycling in Agroecosystems, v.72, p.101-120, 2005.

EMBRAPA. Manual de métodos de análise de solo. 2.ed. Rio de Janeiro: Embrapa-CNPS, 1997. 212p.

ESPINDOLA, J.A.A.; GUERRA, J.G.M.; DE-POLLI, H.; ALMEIDA, D.L. de; ABBOUD, A.C. de S. Adubação verde com leguminosas. Brasília: Embrapa Informação Tecnológica, 2005. 52p.

EVANS, W.B. Nitrogen applications alter tissue and soil N levels but not postharvest quality of Boston lettuce grown on Ohio muck soils. HortScience, v.33, p.443-558, 1998.

FAO. World Health Organization. Guidelines for the production, processing, labelling and marketing of organically produced foods. Rome: FAO-WHO, 2007. 39p. (Codex Alimentarius. CAC/ GL, 32).

FILGUEIRA, F.A.R. Novo manual de olericultura: agrotecnologia moderna na produção e comercialização de hortaliças. 2.ed. rev. amp. Viçosa: UFV, 2003. 412p.

FILLERY, I.R.P. The fate of biologically fixed nitrogen in legumebased dryland farming systems: a review. Australian Journal of Experimental Agriculture, v.41, p.361-381, 2001.
GILLER, K.E.; CADISCH, G. Future benefits from biological nitrogen fixation: an ecological approach to agriculture. Plant and Soil, v.174, p.255-277, 1995.

HANDAYANTO, E.; GILLER, K.E.; CADISCH, G. Regulating N release from legume tree prunings by mixing residues of different quality. Soil Biology and Biochemistry, v.29, p.1417-1426, 1997.

MELLO, J.C.; DIETRICH, R.; MEINERT, E.M.; TEIXEIRA, E.; AMANTE, E.R. Efeito do cultivo orgânico e convencional sobre a vida-de-prateleira de alface americana (Lactuca sativa L.) minimamente processada. Ciência e Tecnologia de Alimentos, v.23, p.418-426, 2003.

NAM, S.Y. Color changes of leaf lettuce during postharvest storage. HortScience, v.35, p.387-519, 2000.

OLIVEIRA, N.G. de; DE-POLLI, H.; ALMEIDA, D.L. de; GUERRA, J.G.M. Plantio direto de alface adubada com "cama" de aviário sobre coberturas vivas de grama e amendoim forrageiro. Horticultura Brasileira, v.24, p.112-117, 2006.

ORMOND, J.G.P.; PAULA, S.R.L. de; FAVERET FILHO, P.; ROCHA, L.T.M. da. Agricultura orgânica: quando o passado é futuro. BNDES Setorial, v.15, p.3-34, 2002.

PEOPLES M.B.; HERRIDGE, D.F.; LADHA, J.K. Biological nitrogen fixation: an efficient source of nitrogen for sustainable agricultural production? Plant and Soil, v.174, p.3-28, 1995.

POULSEN, N.; SØRENSEN, J.N.; JOHANSEN, A.S. Influence on growth conditions on the value of crisphead lettuce. 2. Weight losses during storage as affected by nitrogen, plant age and cooling system. Plant Foods for Human Nutrition, v.46, p.13-18, 1994.

ROVERSI, R.M.; MASSON, M.L. Qualidade da alface crespa minimamente processada acondicionada em atmosfera modificada. Ciência e Agrotecnologia, v.28, p.823-830, 2004.

SANTOS, R.H. dos S.; SILVA, F.; CASALI, V.W.D.; CONDÉ, A.R. Conservação pós-colheita de alface cultivada com composto orgânico. Pesquisa Agropecuária Brasileira, v.36, p.521-525, 2001.

TURAZI, C.M.V.; JUNQUEIRA, A.M.R.; OLIVEIRA, S.A.; BORGO, L.A. Acúmulo de nitrato em alface em função da adubação, horário de colheita e tempo de armazenamento. Horticultura Brasileira, v.24, p.65-70, 2006.

VAROQUAuX, P.; MAZOLlier, J.; ALBAGNAC, G. The influence of raw material characteristics on the storage life of freshcut butterhead lettuce. Postharvest Biology and Technology, v.9, p.127-139, 1996.

Recebido em 8 de janeiro de 2008 e aprovado em junho de 2008 